\title{
Development Trends of Continuing Education in Russia
}

\author{
Marina A. Cherkasova \\ Russian State Social University, Kamensk-Shakhtinsk \\ Email: rusciense@mail.ru, kamensk@rgsu.net
}

\section{Doi:10.5901/mjss.2015.v6n3s1p124}

\begin{abstract}
The dynamism of social life, constantly changing technologies, professions and specialities increases the importance of continuing education, because it is designed to ensure the acquisition, increase or change the qualifications of the individual at any period of his life. However, it is known that the effective activity of the educational institutions is caused by modern produce of different kinds of resources. In modern Russia there is a paradoxical situation: the need to increase skills (and, consequently, higher levels of education) is constantly increasing, which is primarily due to economic reforms, and resources, that satisfy this need, are proportionately decreasing. Decisions on the allocation of funds for the development of the education system mainly depend on local and national government policy, but in the context of the economic crisis there is a tendency of reduced funding of those areas where the opposition will be the least effective, and the resistance will be the least organized. One of such are is the field of education. Today, resource failure of the Russian institutions of continuing education leads, on the one hand, to the outflow of personnel, from the other hand increases his unavailability for the poor strata of society. The growing need of the population of Russia in continuous education and the simultaneous reduction in its resource provision creates that social conflict, which makes difficult the saturation of the institutions of continuing education in Russia with the actual content.
\end{abstract}

Keywords: continuing education, resources, trends of continuing education, forms of continuing education;

\section{Introduction}

The formation of the system of continuous education is carried out in the second half of the XX century under the influence, on the one hand, the high dynamism of the market type of economy of information societies, requiring constant training or retraining of the employee, on the other hand the individual himself, a growth-oriented qualification, change of status positions and self-realization (Polezhaev, V.D. and Polezhaeva M.V., 2009).

The identification of trends of continuing education offers a clarification of the effective development of this system on the basis of the analysis of its functioning in the present and the future. The presence of countertendencies indicates a discontinuity in the processes of the education movement in the direction of a great democracy and efficiency, as in its provision of resources, continuing education affected the economy of a society which is marked by ups and downs of production and the discontinuity of economic growth.

The concept of lifelong education has replaced the consideration of education as a specific and complete stage of socialization and educating of the individual. The concept of considering education as a continuous process, based on the following principles: the prolongation of education throughout the life cycle of the individual; the relationship of all educational structures and levels, which requires the adaptation of programmes and teaching methods, the characteristic of institutions of different levels to each other, and establishing close links between different spheres of activity and tasks of education, democracy education, i.e. its availability to all segments of society.

Continuing education is characterized by a change of the subject of the educational process. It turns on the macro - meso and micro levels of functioning of the social system, qualitatively affecting its content, which allows to define education as a social process. At the macro level is the interaction of the education system with other subsystems of society and reverse impact of the educational process on the economic, political and cultural process based on the principle of sharing resources on educational outcomes. Meso-level represents the dynamics of the educational system, and it's structural and substantive changes are made under the influence of macro-processes. At the micro level, the functioning of the system of continuous education is associated with a change in the choice of occupation and the change of position of the individual in the social structure of society. The result of the relationship of changes at different levels of the process of continuous education is in demand both by society and the individual - social and professional competence. 
Assessment of the significance of the results of the process of continuous education of individuals and groups is carried out according to cultural standards, the most important parameters of which are efficiency and prestige of the institutions of continuing education, defined by the intellectual authority of his staff.

The nature of the process of continuous education, caused by the causal factors, due to their impact on the organization and content of education, based on learning methods from obtaining the knowledge and ability to perform different types of activities taking into account the relevant standards, and also on the external environment through the influence approval of equality of opportunities and citizenship, the institutionalization of culture through the development of innovative trends of the educational system (Hawamdeh, S. and Hussein, A., 2009).

However, the actual internal dynamism and continuity, as the transition from one educational level to another, are formed only in the second half of the XX century. They develop under the influence of, on the one hand, the high dynamism of the market type of economy information societies, requiring constant training or retraining of workers, on the other hand the individual himself, oriented on a growth of qualification, change of status positions and selfactualization. In the framework of continuous education as a social process in contrast to traditional education lay the following principles: prolongation and education throughout the life cycle of the individual as a social demand rate; the relationship of all educational structures and levels to each other; a combination of formal and informal methods of education; democracy of education as its accessibility to all sections of society; developed need of the individual in constant hanging of educational level.

Continuing education process is carried out at three levels: macro-, meso - and micro-level. Macro-level allows us to consider the interaction of the education system with other subsystems and the reverse influence of the educational process on the economic, political and cultural processes on the basis of the principle of sharing resources on educational outcomes. At the micro level (of individual, included in the educational process) the functioning of the system of continuous education is associated with changes in the choice of occupations and changing the positions of the individual to the social structure of society. Meso-level represents the dynamics of the educational systems, which takes place in the structural and substantive changes that are being implemented under the influence of the educational processes at the macro and micro levels.

The result of continuous education is the transformation of a traditional Institute of education due to the formation of new educational structures and coordination mechanisms in the activity, focusing on satisfaction of the qualification, adaptation and integration needs of individuals throughout the life Assessment of the significance of the results of the process of continuous education of individuals and groups is carried out according to cultural standards, the most important parameters of which are efficiency and prestige of the organization of continuing education, defined by the intellectual authority of his staff.

Today continuing education in advanced industrial countries moved from the phase to formation of the phase of the development, i. e. has started to develop at its own base, when the development of education ahead requests of the economic subsystem, and it become more independent in relation to the political system through independent funding sources.

Nowadays state of development of the Russian system of education suggests that there is an institutional structure of continuing education (i.e., the meso-level). They require adjustment of programs and methods of education, typical for institutions of different levels to each other, as well as the establishment of close links between the various spheres of activity and tasks of education. However, in a situation of systemic crisis there is no practical relevance for the development of the continuous education system at the macro level. It is projected on the micro level, where education becomes quasi-continuous, it is meaningfully characterized by the discreteness of the educational stages, which is explained by the dominance of utilitarian attitude to education.

A consequence of the mismatch of the functioning of education at the macro-, meso - and micro level is that quasicontinuous form of education in Russia. In the presence of structural organization the ways of ensuring the continuity of the educational process throughout the life of the individual, at existing financial capability to invest the educational process, with a common value of education among the population, the educational level of demand in the labour market blocks the tendency of the substantial development of education as a continuous social process.

\section{Literature Review}

The problem of continuous education is a field of interdisciplinary research and the successor of the problems of analysis of the educational process in general. A great contribution to its development has made the work of the representatives of pedagogical science. In particular, A. P. Vladislavlev, M. D. Makhlin view education as a socialization process that performs educational functions at different stages of development of a person. 
Of no less importance for the development of education are the works of famous Russian scientists E. V. llyenkov, V. Y. Nechayev, who investigated the subjective aspects of the educational process, namely, looks at education from the point of view of social and cultural development of personality.

Pantosocial aspect of education was considered in the works of F. R. Filippov, V. G., Osipov, M. N. The Rutkevich, O. I. Shkaratan, L. Otal. Based on a systemic-structural analysis (P. Bourdieu, T. Parsons, R. Merton), they considered the function of education in society on the one hand, as a subsystem that supports social order and control; on the other, as a factor of changes in the social position of the individual in society.

The communicative aspect of education, where education is seen as cultural reproduction and rational recognition of the importance of knowledge, develops in the works of J. Habermas, K.G. Flehsing, T. Parsons.

In recent years, in domestic sociological and socio-philosophical studies education is seen as a non-classical system, aimed at creating creative and self-adaptive person living in a rapidly changing world (A. I., Subetto, I. S. Bolotin, O. S. Kozlov). This approach has been developed also at the level of pedagogical researches that aim to identify the optimal model of the organization of education from the point of view of the effectiveness of pedagogical activity. In the pedagogical and socio-pedagogical researches the multi-level system of education is simulated.

\section{The Main Purposes of Continuing Education}

\subsection{Methods and materials}

The theoretic-methodological basis of the research of the author is a systematic approach developed by T. Parsons, according to which economic, political and societal sphere of social life are in the relationship of functional dependence and exchange. Education is an integral element of the societal system of the society and performs the function of reproduction and transmission of cultural sample. Conceptual development of the idea of education as a social process based on a methodological model for the analysis of social processes is proposed by P. Shtompka. It's application to the analysis of the education system have required access to the research concepts of learning as the content of an educational activity. The works of E. V. Ilyenkov, G. P. Schedrovitsky, V. Y. Nechayev, who consider teaching as the development of individual social and cultural experience are used for this.

3.2 The objectives of continuing education of personnel in the production from the position of the employer and employee positions

One of the main purposes of continuing education - expansion and diversification of educational services that complement the basic school or high school training. This recognizes the failure or inability of the base system to teach a person everything that he would have to do during their working lives. Continuing education is equivalent to adult education, since we are talking about different forms of training, professional development and cultural level of the people who have overcome the usual age of basic education.

The objectives of continuing education of personnel in the production from the position of the employer:

- Organization and formation of personnel management.

- Mastering the ability to identify, understand and solve problems.

- Reproduction and integration of personnel.

- Adaptation and innovation Maintaining an appropriate level and professional development.

From the perspective of the employee:

- Acquisition of professional knowledge is the core business.

- $\quad$ The acquisition of knowledge about the "external" organizations that affect the company.

- Development of skills in the planning and organization of production.

- Planning for Lifelong Learning - one of the main components of human resource planning, which includes two stages: the first - forecast quantitative and qualitative composition of employees in the organization for the period under review; second - making plans recruitment, training, retraining and skills development.

The uniqueness of the socio-cultural, economic situation, Russia today is that the need for change in society poses a challenge to the status of human development priorities.

One way to solve this problem may be a realization of the concept of lifelong education, in contrast to the continuous - aimed at specific time frame and the final achievable result. Practice shows that the discontinuous form of training does not cover the wide range of problems that confront the specialists on the basis of modern requirements.

Preparation of the initial vocational education may alternate with difficulty on the basis of the knowledge gained. 
Then work may be interrupted and continued his studies at a higher level. Study may also continue on the job.

The discontinuity of the educational process does not contradict the idea of lifelong learning. Continuing education is designed to ensure the harmonious development of each individual, individualize learning, educate each person is aware of the need to improve the level of knowledge. Each student must be a way to obtain the necessary knowledge to him. At the center of every stage and level of continuous education and training delivered person, the person with their own interests.

\section{The Results and Discussion}

Continuing education is characterized by a change of the subject of the educational process. It grounds on the macro meso and micro levels of functioning of the social system, qualitatively affecting its content, which allows to define education as a social process. At the macro level the interaction of the education system with other subsystems of society and reverse the impact of the educational process on the economic, political and cultural process based on the principle of sharing resources on educational outcomes is realized. Meso-level represents the dynamics of the educational system, and carrying in it structural and substantive changes are made under the influence of macro-processes. At the micro level, the functioning of the system of continuous education is associated with a change in the choice of occupation and the change of position of the individual in the social structure of society. The result of the relationship changes at different levels of the process of continuous education is in demand both society and the individual - social and professional competence.

Assessment of the significance of the results of the process of continuous education of individuals and groups is carried out according to cultural standards, the most important parameters which are efficiency and prestige of the institutions of continuing education, defined the intellectual authority of his staff.

The structures of continuing education are University centers, because they possess a well-developed scientific infrastructure and relevant experience of the implementation of the educational process. (Otala, L., 1995)

The effective functioning of universities as basic structures of continuing education depends on their orientation to adult learners as a long-term clients of universities. At the organization of the learning process for adult students it is necessary to consider their demanding attitude and result oriented nature; they have experience that allows to quickly learn new things; they are more motivated in study, the results of which can be used in practice.

Nowadays alternative non-formal education in correspondence higher educational institutions, which turned out to be receptive to new technologies, is developing. The development of new educational technologies is a daunting task to form the radically new educational practices that entail a change in the organization of educational process.

Thus, the model of "open education" is an alternative organizational form of the traditional education system, since it is based on other organizational principles: free admission to College (without appropriate education and examinations); certain freedom in shaping their own individual programs; the ability to change the educational trajectory; mastering of material at a convenient time, in a convenient location and at an acceptable pace (distance learning). Development of the model of "open education" in the framework of the system of continuing education is focused on the search for new organizational forms of education without interruption from main activity, allowing to extend the range of consumers of educational services who are unable (for various reasons, for example, demographic, socio-economic and other) to avail of the traditional educational structures.

New forms of continuing education are units of distance education in a traditional University. (A detailed overview of informal forms of education continuing education provides T. Voronina., 1997)

The main problem of distance education as a form of continuing education is introduction in the educational process of new technologies (work knowledge bank, project work, training, etc. involving the use of a computer) that may in time to expand and change the traditional model of educating, based on the text and interpretation of knowledge by the teacher (Jean, Gray, 2008).

The use of distance educating media - e-books, audio and video products, TV programs directly reflected on the methods of organization of educational process. Learning of the material by the student is carried out at a convenient time, in a convenient location and at an acceptable pace. Teacher-tutors are in contact with students with the help of different types of communication (phone, mail, email). Their task is the management of independent work of students: setting aims and problems in obtaining the knowledge, creation of forms and methods of educating, and monitoring of the educating process, etc.

The distance educating program is developed in accordance with the modular principle, and not the curriculum. The student is encouraged to create an individual program that meets their individual needs, from a set of independent courses that create a holistic understanding of a particular subject area. A similar approach to the development of 
educating programs allows its modernization, taking into account social and educational tasks, the specific number of students. A similar approach to the development of educating programs allows its modernization, taking into account social and educational tasks, the specific number of students (Cherkasova, M.A., 2005).

Consortium of universities is a promising form of continuing education for the Russian, it is a commercial enterprise, providing communicative and administrative services to provide training courses for distance educating on the basis of a variety of educational technologies developed within the consortium of traditional universities. The consortium can provide various courses, but more importantly, it provides the ability to remotely obtain degrees and certificates bachelor's and master's of universities, which it includesThis institutional model is extremely important, because it allows to effectively integrate educational resources many of the traditional universities on the basis of modern technologies.

Recently another form of continuing education: virtual classrooms and universities began to emerge. The education in virtual classrooms is organized by specialists, for example, in one of the major projects programme of the European Community. The success of commercial general purpose system for computerized conferences, which has 800 thousand users worldwide, shows how one can organize the work of thousands of students in virtual classrooms. The closest to the practical implementation of the model of the virtual University is a model in which the educational process is based on the technology of electronic mail, computer conferencing, remote access, file transfer and synchronous communications.

The use of new technologies contributes to the increase in the trend of productivity in education, dramatically increasing the cost efficiency. The result is formation of an educational system of post-industrial, informational society - a global open, flexible education and learning throughout a person's life. In order of Russian higher school to be competitive in these days emerging the global market of educational services, it is necessary to use new educational technologies on the basis of modern computer and telecommunication systems.

One of the most important principles of continuous education is the availability of different segments of society. The availability of continuing education is student participation in payment of continuing education.

Nowadays there is the basic agreement on the universality of continuing education in society. It is expressed in various continuing education programs (e.g., European continuing education program), as well as normative documents (Russian Federation Law "On education", "On higher and postgraduate professional education"). The development of the principle of universality of continuing education, as the possibility of combining different educational stages and structures, identifies the trend, according to which continuing education is recognized as a priority education of policy of different States.

Structures of continuing education are University centers, because they possess a well-developed scientific infrastructure and relevant experience of the implementation of the educational process.

The effective functioning of universities as basic structures of continuing education depends on their orientation to adult educating as a long - term clients of universities.

At the organization of the learning process for adult students it is necessary to consider their demanding attitude and result oriented nature; they have experience that allows to quickly learn new things; they are more motivated to study, the results of which can be used in practice. More important for them is tutoring, guidance, advice, training aids for teaching.

Thus, in the framework of the principle of integrity (training throughout the life-cycle of the individual), the main trend of continuing education is the focus on the adult as a student, because now people are forced to switch to daily educational activity. Organization of educational process for adult students involves the use of various forms, means and methods of training.

Today, alternative non-formal education in correspondence of higher educational institutions, which turned out to be receptive to new technologies is developing. The development of new educational technologies is a daunting task to form the radically new educational practices that entails a change in the organization of the educational process.

Thus, the model of "open educating" is an alternative organizational form of the traditional education system, since it is based on other organizational principles: free admission to College (without appropriate education and examinations); certain freedom in shaping their own individual programs; the ability to change the educational trajectory; development of material at a convenient time, in a convenient location and at an acceptable pace (distance learning). Development of the model of "open education" in the framework of the system of continuing education focuses on the search for new organizational forms of education without interruption from activity allowing to extend the range of consumers of educational services who are unable (for various reasons, for example, demographic, socio-economic and other) to avail of the traditional educational structures.

Units of distance education in a traditional University are new forms of continuing education.

The main problem of distance educating as a form of continuing education the introduction in educational process 
of new technologies (work with knowledge bank, project work, training, etc. involving the use of a computer) that may in time to expand and change the traditional model of learning, based on the text and interpretation of knowledge by the teacher.

The use of distance learning media - e-books, audio and video products, TV programs directly reflects on the methods of organization of educational process. Learning of the material by a student is carried out at a convenient time, in a convenient location and at an acceptable pace. The teacher - tutor are in connection with students with the help of various forms of communication (phone, mail, email). His task is the management of independent work of students: setting aims and purposes in obtaining knowledge. its transfer, creating forms, training methods, as well as monitoring the process of learning and other. The distance educating program is developed in accordance with the modular principle, and not the curriculum. The student is encouraged to create an individual program that meets their individual needs, from a set of independent courses that create a holistic understanding of a particular subject area. A similar approach of program design of training programs allows its modernization, taking into account social and educational tasks, the specific number of students.

Promising for the Russian form of continuing education is a consortium of universities and commercial enterprise, providing communicative and administrative servants by providing training courses for distance education on the basis of a variety of educational technologies developed within the consortium of traditional universities. The consortium can provide various courses, but more importantly, it provides the ability to remotely obtain degrees and certificates bachelor's and master's in universities, which it includes. This institutional model is extremely important, because it allows to effectively integrate educational resources of many of the traditional universities on the basis of modern technologies.

Another new institutional form of distance University education called TV-university is based on combining the resources of traditional universities, it is truly a much higher level than in the case of a University consortium. TVuniversity is the mutual work of a number of independent universities in an integrated curriculum based on modern telecommunication technologies. Model of a modern University education is most clearly embodied in the activities of the National technical University USA, which combines the resources of 46 leading universities of the country and offers programs that provide a master's degree through distance learning with the help of satellite television and other telecommunication technologies. Established in 1984; NTU is now one of the largest technical universities in the USA.

One of the most important principles of continuous education is the availability of different segments of society. The availability of continuing education is student participation in the education payment.

Recently another form of continuing education: virtual classrooms and universities began to emerge. Organization of education in virtual classrooms is carried out by specialists, for example, in one of the major projects programme of the European Community. The success of commercial general purpose system for computerized conferences, which has 800 thousand users worldwide, shows how one can organize the work of thousands of students in virtual classrooms. Closest to the practical implementation of the model of the virtual University is a model in which the educational process is based on the technology of electronic mail, computer conferencing, remote access, file transfer and synchronous communications.

\section{Conclusions}

The use of new technologies contributes to the increase in the trend of productivity in education, which dramatically increase the cost efficiency. As the result an educational system of post-industrial, informational society - a global open, flexible education and self-learning throughout life is forming. On these days emerging global market of educational services, it is necessary for Russian higher school to use new educational technologies on the basis of modern computer and telecommunication systems in order to be competitive.

Education for human is only a means to adapt to changes in the social environment, often forced, but not inner necessity, much less a means of self-realization. What kind of continuity then we can say whether it is at all, if the majority of the main incentive is the final result (diploma, academic degree, etc.). Thus, the concept of continuing education in the form in which it is understood in modern science as "lifelong education" - a beautiful play on words, since the resumption of continuity implies consistency, and education - the emergence of something new, on the basis of preexisting but lost its relevance, a new image of the famous object, the object of this known or unknown object.

The problem is that continuing education requires not only the educational activity in the external environment, but requires constant internal educational change under the influence of newly developed knowledge that for the modern individual and the system is back-breaking labor, because he was used to, it is convenient, and much easier to change something outside or make visible changes, while remaining unchanged internally. 


\section{References}

Otala, L., 1995. Finnish approach to Lifelong Learning. -European Higher Education. 8-12 pp.

A detailed overview of informal forms of education continuing education provides T. Voronina., 1997 - See: Voronina T. Thinking about the prospects of the graduate school at the conference on philosophy of education. // The Bulletin of the graduate school. No. 5. 3-6 pp.

Cherkasova, M.A., 2005. Continuing education: concepts and experience/s.-Grew up with. state technical University (NPI). Novocherkassk: the UOC "Nabla" SRSTU (NPI). 124 pp.

Polezhaev, V.D. and M.V. Polezhaeva, 2009. Introduction of continuing education in Russia. международный журналэксперименталь ного образования. №1. 19-20 pp.

Hawamdeh, S. and Hussein, A., 2009. Perceived Quality of Teaching in a Problem-Based Learning (PBL) Approach. Journal of Health Professions Education. May 22.

Jean, Gray, 2008. The teacher's teacher. Journal of Continuing Education in the Health Professions 02/2008; 28(1):56 pp. 